\title{
PLACA CIMENTÍCIA PARA VEDAÇĀO VERTICAL PRODUZIDA A PARTIR DE ARGAMASSA COM POLIESTIRENO EXPANDIDO
}

\author{
M. SILVA \\ Mestrando \\ Universidade Federal do Pará \\ Pará; Brasil \\ max_weverton19@hotmail.com \\ E. GOMES \\ Graduanda \\ Universidade Federal do Pará \\ Pará; Brasil \\ Eli_mayara@hotmail.com
}

\author{
C. MENEZES \\ Graduanda \\ Universidade Federal do Pará \\ Pará; Brasil \\ carolinemenezes10@gmail.com \\ L. CORDEIRO \\ Professora \\ Universidade Federal do Pará \\ Pará; Brasil \\ lupcordeiroo@gmail.com
}

\section{RESUMO}

O objetivo deste trabalho é caracterizar placas cimentícias leves para vedação vertical interna a partir de argamassas produzidas com pérolas de poliestireno expandido (EPS). A placa cimentícia é constituída de uma argamassa composta de cimento, areia natural, pérolas de poliestireno expandido e aditivo superplastificante; com uma tela polimérica como material de reforço. Foram produzidas placas com as dimensões de 250mm x 250mm x 15mm, conforme a NBR 15498 (ABNT, 2016), e ensaiadas de resistência à flexão, densidade aparente e absorção de água. As placas foram testadas na condição de equilíbrio e classificadas conforme categoria B da NBR 15498 (ABNT, 2016). O teor de de incorporação de EPS nas placas foi de $0 \% 10 \%, 20 \%$ e 30\%, em volume. Observou-se uma relação linear inversa entre a queda de resistência à flexão e a densidade aparente das placas. Os resultados mostram que é possível produzir placas cimentícias com argamassas de EPS com um teor de incorporação de até $20 \%$ de EPS.

Palavras-chave: placa cimentícia, poliestireno expandido(EPS), argamassa leve.

\section{ABSTRACT}

The objective of this paper is to characterize lightweight cementitious boards for internal vertical sealing from mortars produced with expanded polystyrene (EPS) beads. The cementitious slab consists of a mortar composed of cement, natural sand, expanded polystyrene beads and superplasticizer additive; with a polymeric mesh as reinforcement material. Plates with dimensions of $250 \mathrm{~mm} \times 250 \mathrm{~mm} \times 15 \mathrm{~mm}$ were produced, according to NBR 15498 (ABNT, 2016), and tested for flexural strength, bulk density and water absorption. The plates were tested at equilibrium and classified according to category B of NBR 15498 (ABNT, 2016). The incorporation content of EPS into the plates was 0\% 10\%, 20\% and 30\% by volume. An inverse linear relationship was observed between the drop in flexural strength and the apparent density of the plates. The results show that it is possible to produce cementitious slabs with EPS mortars with an embedding content of up to $20 \%$ EPS.

Keywords: cementitious boards, expanded polystyrene (EPS), lightweight mortar.

\section{INTRODUÇÃO}

As novas tecnologia tem atingindo vários âmbitos dentro da construção civil, é uma busca que relaciona os processos de produção com novos materiais ou novas formas de utilização de materiais, assim aprimorando estudos que já foram realizados, ou seja, nessa linha de lógica já foram realizados várias pesquisas para a uma nova forma de utilizar o poliestireno expandido (EPS), mas neste trabalho tem-se o objetivo de adicionar na produção de argamassa e melhorar o desempenho da matriz cimentícia na execução de placas cimentícias para vedação. Segundo Khatib (2019), a utilização desse tipo de material tem como vantagem reduzir a quantidade de materiais enviados para aterros, aumentaria seu uso nas matrizes cimentícias e por conseguinte diminuiria o uso de agregados naturais não renováveis, visando assim a sustentabilidade no sistema de produção. 
O poliestireno expandido (EPS) é um polimérico que no trabalho foi usado em forma de pérolas, estas são formadas de microcélulas fechadas, com aproximadamente $2 \%$ de poliestireno e $98 \%$ de vazios contendo ar, fisicamente estável. As características mais significativas desse material é sua baixa densidade, realizando assim uma diminuição também da densidade do concreto ou argamassa que usa como agregado na matriz cimentícia, tem baixa absorção de água, pois é hidrofóbico. Em relação a sua durabilidade é resistente ao envelhecimento ou degradação, pois é um material não reagente e com isso não ocorre proliferação de microrganismos na mistura (Maaroufi et al, 2018).

Nesse âmbito em relação às características do EPS, pode-se perceber que incorporar ele na matriz cimentícia de uma placa, trará uma boa alternativa para as placas cimentícias de vedação, pois a utilização delas acaba suprindo o uso da alvenaria, que possibilita na redução do peso e carga exercida sobre a estrutura da obra (Junior, 2019). O uso de placas cimentícias comercialmente é condicionado ao atendimento de especificações técnicas contidas nos normativos, como a norma de desempenho das edificações habitacionais, NBR 15575-4 (ABNT, 2013), que trata dos sistemas de vedações verticais internas e externas. Outra norma que condiciona o uso das placas é a NBR 15498 (ABNT, 2016), que trata especificamente de placas de fibrocimento, trazendo os requisitos e métodos de ensaios. Essas normas especificam os parâmetros a serem seguidos, principalmente no tocante a geometria da peça, resistência a flexão, permeabilidade, estanqueidade, conforto térmico e acústico, resistência ao fogo, entre outros.

Em função dos fatores mencionados, buscou-se determinar um teor ideal de poliestireno expandido incorporado na argamassa para produção das placas cimentícias com finalidade em vedação vertical, mas que pudesse obter resultados favoráveis para resistência a flexão, densidade aparente e absorção de água. Desse modo, o objetivo deste trabalho é caracterizar placas cimentícias leves para vedação vertical interna a partir de argamassas produzidas com pérolas de poliestireno expandido (EPS).

\section{METODOLOGIA}

Os procedimentos experimentais empregados tem por objetivo contribuir para o estudo de novas tecnologias de sistemas construtivos, através do estudo da produção de placas cimentícias (com dimensões de $250 \mathrm{~mm} \times 250 \mathrm{~mm} \times 15 \mathrm{~mm}$ ) constituidas a partir de argamassas produzidas com a incorporação de pérolas de poliestireno expandido (EPS). Desse modo, foram produzidas placas cimentícias com a finalidade de vedação vertical interna, de classe B e caracterizadas conforme as indicações da NBR 15498 (2016), que trata dos requisitos e métodos de ensaios de placas de fibrocimento. Serão realizados os ensaios de a resistência à tração na flexão, densidade aparente e absorção de água das placas, conforme indicações da NBR 15498 (2016). As placas produzidas foram submetidas a cura submersa e ensaiadas na idade de 28 dias.

Os materiais usados neste trabalho foram: cimento Portland composto com escória de alto forno, tipo CP II E - 32; agregado miúdo natural, com módulo de finura de 2,62 e com dimensão máxima de 1,18 $\mu \mathrm{m}$; aditivo superplastificante $\mathrm{e}$ pérolas de poliestireno expandido com diâmetro de até 3mm (Figura 1). Os valores de massa específica desses materiais são descritos na Tabela 1 . Como material de reforço às placas cimentícias, será usada tela hexagonal com malha de $1 / 2$ polegada de polietileno de alta densidade.

Tabela 1 - Massa específica dos materiais utilizados.

\begin{tabular}{c|c|c|c}
\hline Cimento $\left(\mathrm{g} / \mathrm{cm}^{3}\right)$ & Areia $\left(\mathrm{g} / \mathrm{cm}^{3}\right)$ & EPS $\left(\mathrm{g} / \mathrm{cm}^{3}\right)$ & Superplastificante $\left(\mathrm{g} / \mathrm{cm}^{3}\right)$ \\
\hline 3,1 & 2,66 & 0,015 & 1,09 \\
\hline
\end{tabular}




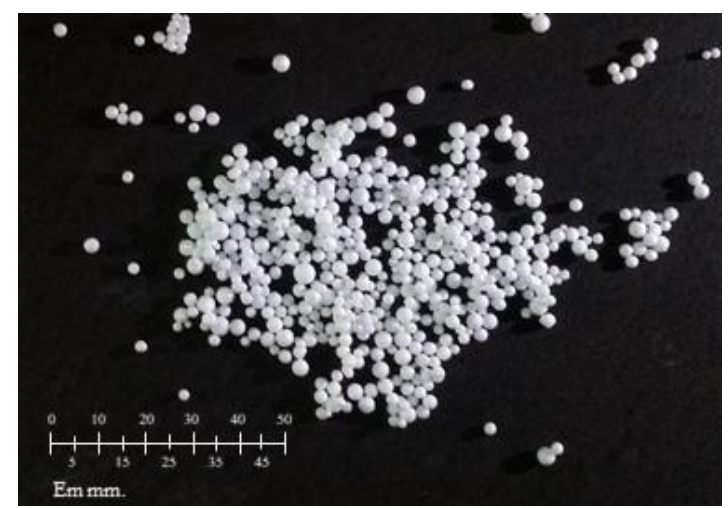

Figura 1: Pérolas de poliestireno expandido usadas no programa experimental.

Para esse estudo foram produzidas quatro famílias de placas cimentícias. Uma família controle, produzida sem a presença de pérolas de EPS, essa amostra foi produzida com a proporção de cimento e areia de um para três. As demais famílias possuem pérolas poliestireno expandido, em proporções distintas de 10\%, 20\% e 30\%, incorporadas em relação ao volume total da argamassa anidra (Tabela 2). A quantidade de água foi determinada através de estudo preliminar, a partir do traço "T 3 30\%", com a determinação de uma consistência que possibilitasse uma boa trabalhabilidade e homogeneidade da argamassa. A partir de então o superplastificante é responsável na manutenção da consistência da argamassa sem o acréscimo de água na mistura.

Tabela 2 - Traços unitários das argamassas leves para produção das placas cimentícias.

\begin{tabular}{c|c|c|c|c|c}
\hline Família & Cimento & Areia & EPS & Água/Cimento & Superplastificante \\
\hline T 3 0\% & 1 & 3,00 & 0,000000 & 0,43 & $0,87 \%$ \\
\hline T 3 10\% & 1 & 2,15 & 0,002968 & 0,43 & $0,15 \%$ \\
\hline T3 20\% & 1 & 1,98 & 0,006562 & 0,43 & $0,147 \%$ \\
\hline T3 30\% & 1 & 1,47 & 0,009842 & 0,43 & 0 \\
\hline
\end{tabular}

No estado fresco, as argamassas foram realizados os ensaios de determinação de densidade no estado fresco (citar a norma) e determinação do índice de consistência, fixada no valor de $240 \mathrm{~mm} \pm 10 \mathrm{~mm}$, valor ao qual garante-se uma fluidez da argamassa e não ocorre segregação do EPS na matriz. segundo a norma NBR 13276 (ABNT, 2016).

A mistura dos materiais foi dada a partir de uma adaptação da NBR 16541 (ABNT, 2016), pois o EPS foi incluso na mistura após uma primeira homogeneização do restante dos materiais, com velocidade de rotação em torno do eixo de 140 rpm. Com isso, o preparo da argamassa seguiu conforme fluxograma apresentado na Figura 2.

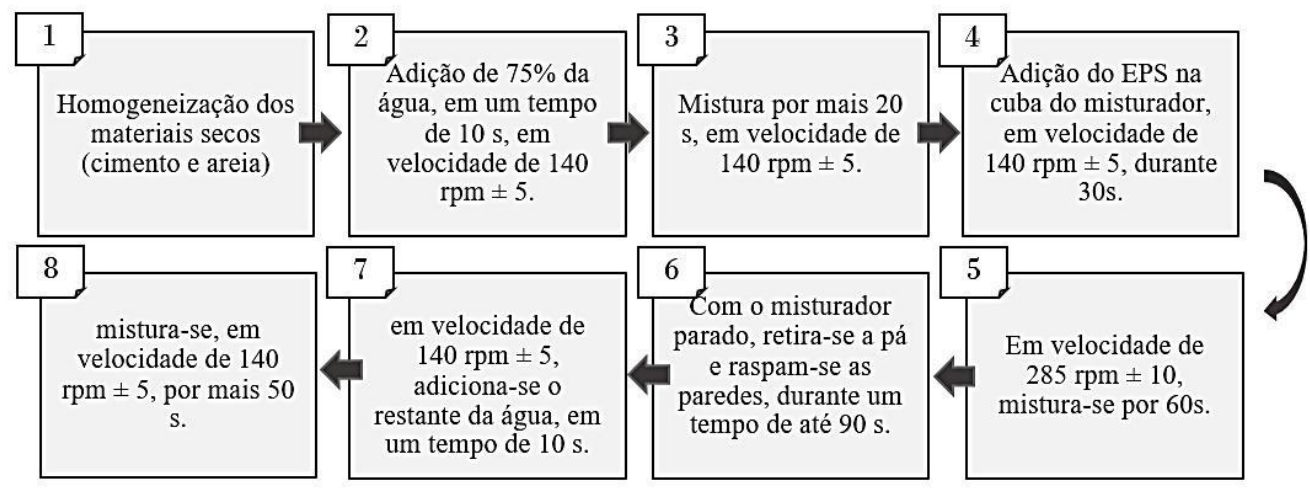

Figura 2 - Fluxograma de atividades para produção da argamassa 
A moldagem das placas foi executada com a utilização de fôrmas metálicas com dimensões internas de $25 \mathrm{~cm} \times 25 \mathrm{~cm} \times$ $1,5 \mathrm{~cm}$. O processo de moldagem foi realizado em três etapas, conforme procedimento realizado por AZEVEDO (2018). Sendo assim, o processo passou pela aplicação da argamassa sobre a fôrma metálica até o preenchimento de $50 \%$ do volume e, logo em seguida, realização do adensamento através da mesa de consistência (Figura 3); disposição da tela plástica sobre a argamassa (Figura 4); e, por fim, a aplicação do restante da argamassa, adensamento da argamassa e regularização da superfície (Figura 5).

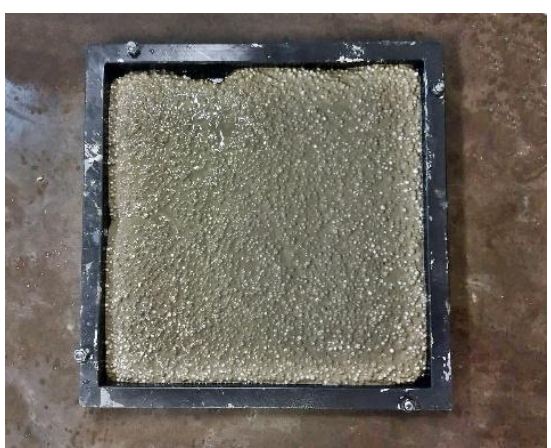

Figura 3: Primeira camada de argamassa leve para a produção de corpo de prova para a placa cimentícia.

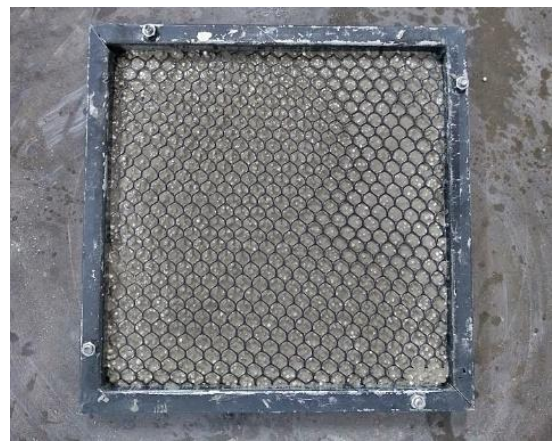

Figura 4: Posicionamento da tela plástica na entre as duas camadas de argamassa.

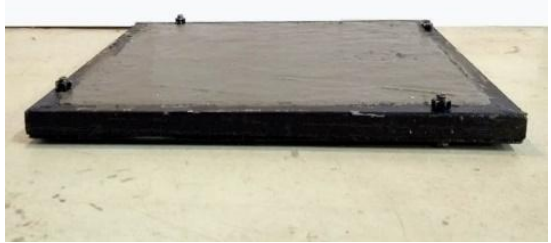

Figura 5: Corpo de prova da placa cimentícia moldada nas dimensões de $25 \mathrm{~cm} \times 25 \mathrm{~cm}$.

O ensaio de resistência à tração na flexão foi realizado em uma máquina universal a uma taxa de carregamento de 0,1 kN/s. Foram usados como apoios barras lisas de aço, com diâmetro de 10mm, dentro dos limites exigidos na NBR 15498 (2016) (Figura 6).

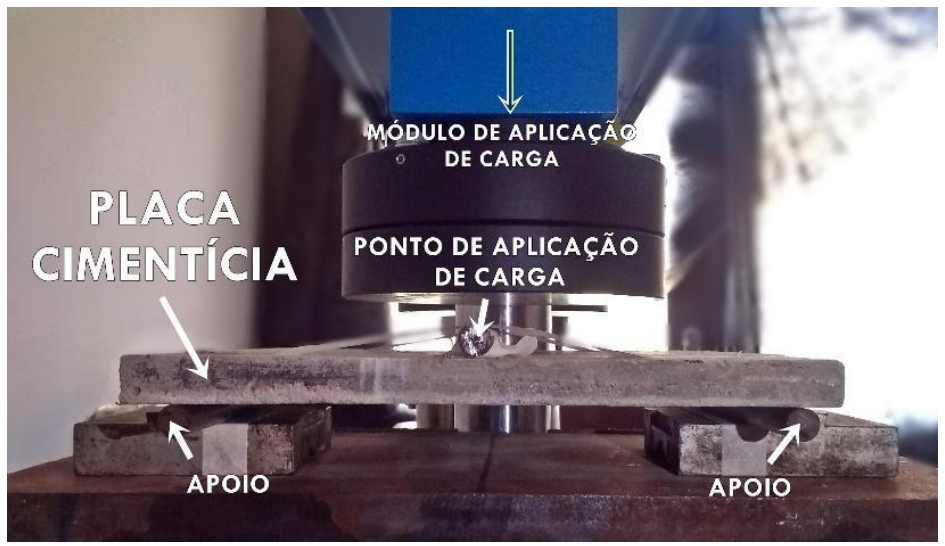

Figura 6: Esquema de ensaio de resistência à flexão dos corpos de prova das placas cimentícias.

\section{RESULTADOS}

As argamassas leves foram misturadas conforme procedimento adaptado da NBR 16541 (ABNT, 2016) descrito. No estado fresco, foram realizados os ensaios de densidade da massa no estado fresco NBR 13278 (ABNT, 2005) e de determinação do índice de consistência NBR 13276 (ABNT, 2016). Os resultados do ensaio de densidade de massa no estado fresco estão apresentados na Tabela 3. Com isso, constatou-se que a incorporação de pérolas de poliestireno expandido atuam na redução significativa da densidade do compósito desde sua mistura, no estado fresco. Observou-se que a redução da densidade da argamassa no estado fresco foi de até 82\%, para as amostras da família T3 $30 \%$ em comparação às de referência (Tabela 3).

Tabela 3 - Densidade das argamassas no estado fresco em $\mathrm{kg} / \mathrm{m}^{3}$.

\begin{tabular}{c|c|c|c|c}
\hline Família & T 30\% & T 3 10\% & T3 20\% & T3 30\% \\
\hline T 3 0\% & $2.189,66$ & 2049,48 & 1933,72 & $1.797,93$ \\
\hline
\end{tabular}


O desempenho de uma argamassa depende, entre outros fatores, de suas características no estado fresco. A trabalhabilidade é a propriedade do material que identifica sua aptidão para ser empregado com determinada finalidade sem perda de homogeneidade (Petrucci, 2005). Com os materiais empregados e a consistência fixada, foi possível obter uma argamassa com boa trabalhabilidade para a produção das placas cimentícias, uma vez que apresentaram homogeneidade entre os materiais, assim como coesão e boa capacidade de retenção de água, observada visualmente (figura 7).

Outro fenômeno de destaque da argamassa no estado fresco foi a ausência da ocorrência de "flutuação dos agregados", que ocorre durante a mistura ou manuseio o concreto leve, com a sedimentação da argamassa, uma vez que ela possui densidade muito superior à dos agregados leves. Rossignolo (2009) afirma que esse fenômeno pode ser evitado realizando a dosagem de concretos com coesão e consistência adequados, pelo controle da relação água/cimento, teor de agregados miúdos e ainda, o uso de adições minerais. No caso deste experimento, o controle da água, usando o superplastificante como mecanismo de compensação para a garantia da consistência, foi fundamental para a garantia da homogeneidade (figura 8).

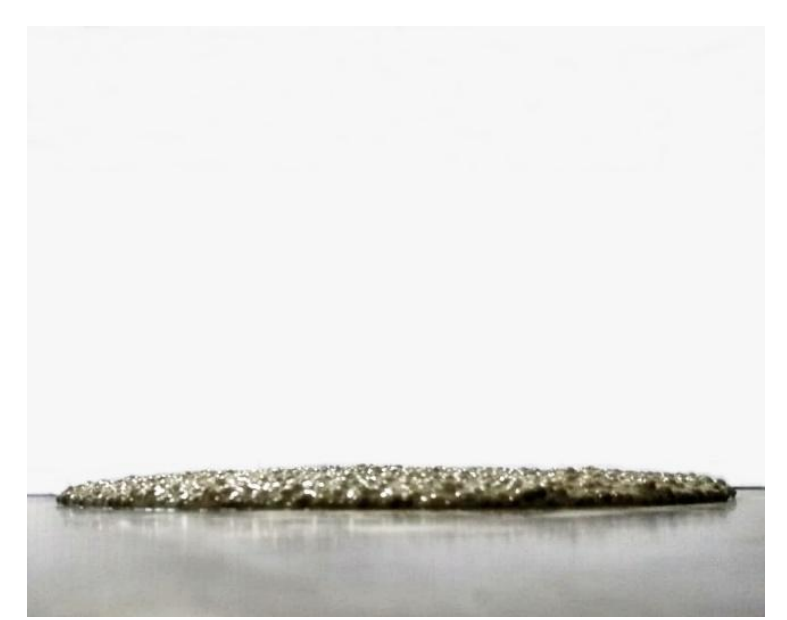

Figura 7: Consistência da argamassa leve com poliestireno expandido, vista lateralmente.

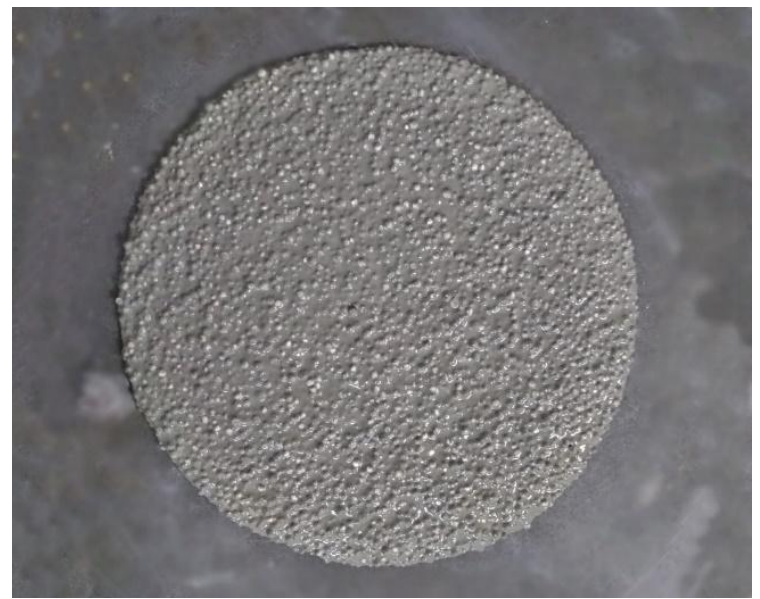

Figura 8: Consistência da argamassa leve com poliestireno expandido, com visão superior.

Em relação ao estado endurecido, observou-se uma queda de resistência a flexão dos compósitos a medida em que foram incorporadas as pérolas de poliestireno expandido (Figuras 9 e 10). O uso de agregados leves proporcionam uma redução da densidade do compósito, por outro lado ocorre uma perda das propriedades mecânicas (Banawair et al., 2019). Da mesma forma que os outros agregados leves, a incorporação de poliestireno expandido em matrizes cimentícias produz materiais com propriedades mecânicas mais baixas (Ranjbar e Mousavi, 2015).

É importante ressaltar que a qualidade do material não pode ser determinada somente pelos seus valores de resistências, uma vez que dependendo da aplicação, vários fatores devem ser levados em conta para determinar se o material possui um bom desempenho. As placas cimentícias não exigem elevadas resistências mecânicas, porém baixa densidade e baixa absorção de água são propriedades que qualificam um material para essa aplicação.

As placas cimentícias são elementos de vedação vertical e, sendo assim, precisam possuir uma resistência mínima para que possa garantir o uso e segurança dos usuários das edificações. A NBR 15498 (ABNT, 2016) apresenta os requisitos de resistência à tração na flexão, categorizando as placas da classe $\mathrm{B}$ em cinco categorias, da categoria 1 até a categoria 5. Os materiais são categorizados de acordo com o valor mínimo atingido do ensaio de resistência à flexão das placas. Os valores mínimos a serem alcançados das placas entre as categorias 1, 2, 3, 4 e 5 são de $4 \mathrm{MPa}, 7 \mathrm{MPa}, 10 \mathrm{MPa}, 16 \mathrm{MPa}$ e $22 \mathrm{MPa}$, respectivamente. Por outro lado, a norma especifica que os painéis devem atingir no mínimo $70 \%$ dos valores mínimo na direção de sua menor resistência.

Em relação a propriedade de resistência a flexão das placas cimentícias, os resultados obtidos mostram que é possível a fabricação de painéis cimentícios para o uso de vedação vertical. Os dados obtidos do ensaio de tração na flexão mostram que os traços "T3 10\%" " "T3 20\%" podem ser classificados com segurança na categoria 1, assim como o traço controle, “T 3 0\%”. O traço “T3 30\%” apresentou resistência à flexão média de 3,19 MPa, inferior ao limite da categoria 1, porém 
esse resultado é de aproximadamente $80 \%$ do limite inferior da categoria, o que viabiliza o traço para a produção de placas cimentícias (Figura 10).

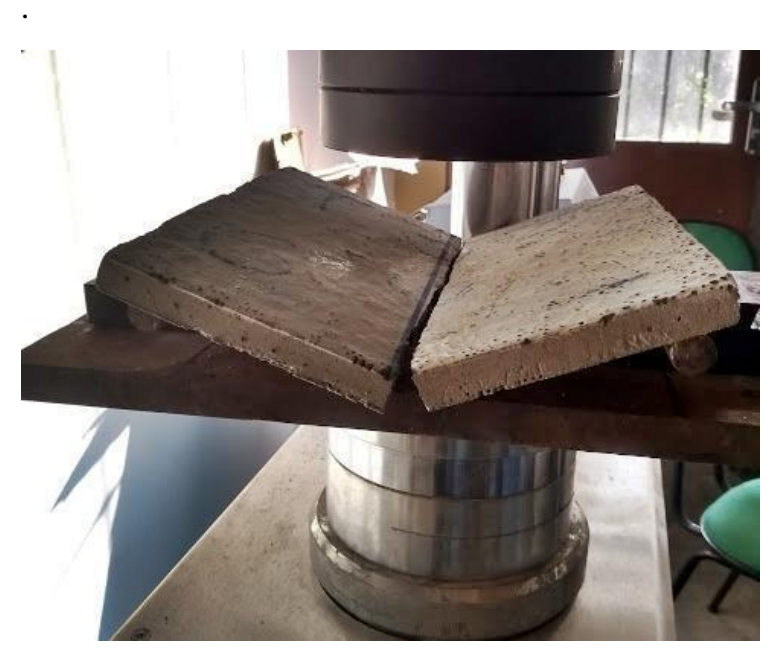

Figura 9: Placa cimentícia após a ruptura no ensaio de resistência à flexão.

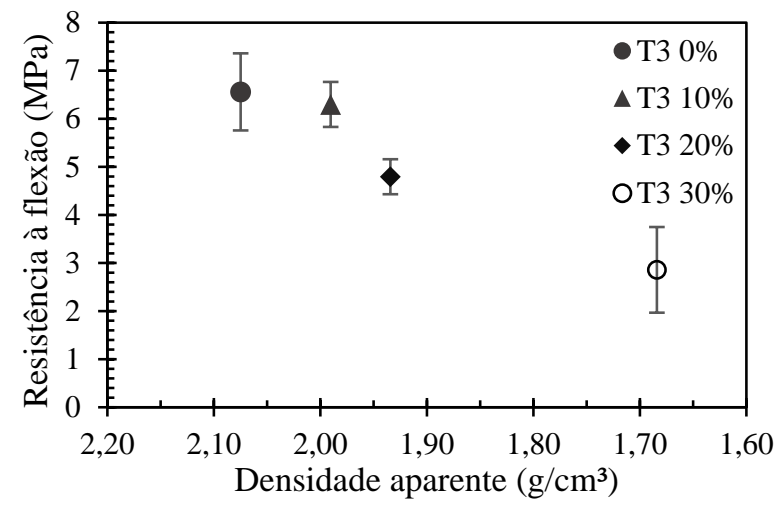

Figura 10: Resultados de resistência à flexão das placas cimentícias de classe $\mathrm{B}$.

A incorporação de EPS teve influência significativa na redução da densidade aparente das placas cimentícias (Figura 11). Nesse sentido, o traço controle apresentou uma densidade aparente média de $2,18 \mathrm{~g} / \mathrm{cm}^{3}$, e as placas produzidas com poliestireno expandido mostraram uma redução na densidade a medida em que foi aumentado o teor de incorporação. Foi possível uma redução percentual na densidade aparente média de 8,72\%, 16,06\% e 23,39\%, entre as famílias "T3 10\%", "T3 20\%" e "T3 30\%, respectivamente. A NBR 15498 (ABNT, 2016) não apresenta exigência quanto ao valor de densidade aparente das placas, apenas exige que o fabricante especifiquem na documentação o valor. Desse modo, não há impedimento quanto a essa propriedade para uso em vedação vertical das placas com EPS. (Figura 11)

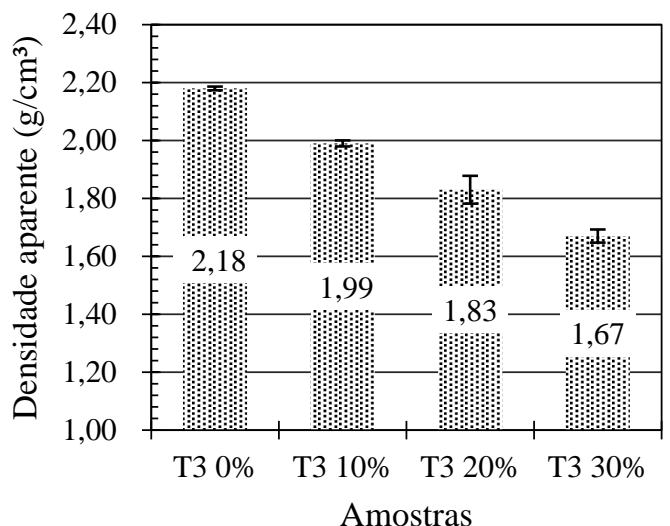

Figura 11: Resultados do ensaio de densidade aparente.

A absorção depende de muitos fatores, incluindo: (a) proporção de materiais na mistura; b) a presença de aditivos químicos e de materiais cimentícios suplementares; c) a composição e as características físicas dos componentes cimentícios e dos agregados; d) teor de ar incorporado; e) o tipo e a duração da cura; f) o grau de hidratação ou idade; g) a presença de microfissuras; h) a presença de tratamento de superfície, como a presença de selantes; e i) método de aplicação, incluindo consolidação e acabamento (ASTM C1585, 2004). Nesse caso, o agregado leve foi o material que teve influência significativa na variação da absorção de água entre as placas estudadas. Os resultados do ensaio de absorção mostram um aumento na absorção de água nas famílias das placas com EPS. Tal aumento pode estar relacionado ao fato de o EPS ser um material hidrofóbico e que, quando presente em matriz cimentícia, promove a formação de uma ligação frágil entre a pasta e o agregado leve, a qual pode funcionar como caminho preferencial para absorção de água. 


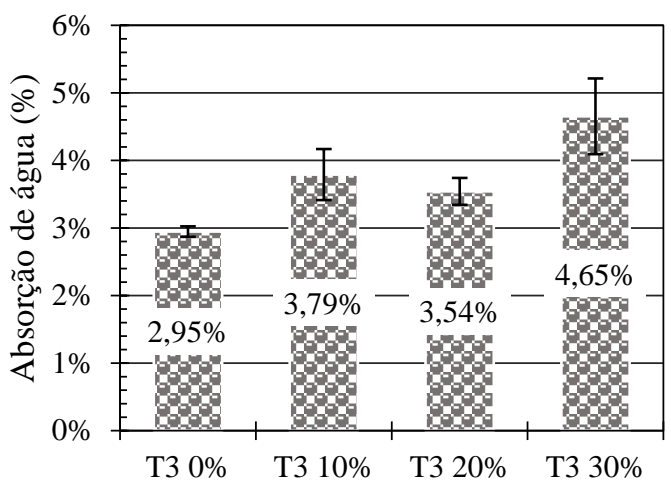

Amostras

Figura 12: Absorção de água.

Painéis cimentícios com baixa densidade são materiais que resultam em benefícios frente a outros tipos de painéis ou sistemas construtivos tradicionais. O uso de placas cimentícias leves resulta na obtenção de um sistema de vedação com menor peso específico, o que acarreta na redução do peso próprio da estrutura e com isso, economia de materiais e recursos na sistema estrutural da edificação. Painéis pré-fabricados leves podem melhorar a produtividade da mão de obra, uma vez que melhora a facilidade de manuseio e transporte do material.

No âmbito patológico entende-se que o cuidado no processo de realização e a aplicabilidade final são importantes para que as placas cimentícias tenham uma presença minima de qualquer patologia que possam estar vunerável, para que com isso não reduza a sua vida útil. As placas com a incorporação do EPS quando analisadas pelos valores de resistência foi verificando, que atingiram um valor minímo, dessa forma podendo deixar ao longo do tempo os componetes dessa placa vuneráveis a patológia mais presentes em placas, que são a presença de fissuras. Sendo que essas fissuras podem surgir pelo erfoço que a placa sofre da estrutura ao longo do tempo, mesmo sendo com uma aplicação de vedação interna, pois o uso externo também permitiria a exposição a intempérie. Um estudo em relação a esse tipo de problema nas placas apresentou que isso também é proveniente de uma mão de obra não qualificadada, pois percebeu - se que o não cuidado do manuseio das placas ocasionaria esse tipo de consequência (Barbosa e Menezes, 2019).

\section{CONCLUSÕES}

Com a execução do programa experimental pôde-se notar que é possível a produção de placas cimentícias com a incorporação de poliestireno expandido, no tocante aos ensaios analisados. Desse modo, elas foram classificadas na categoria 1, da classe B, com a ressalva de que o traço com teor de 30\% "T3 30", atingiu resistência inferior ao limite mínimo, porém superior aos 70\%, comentado pela norma. Foi possível obter no estado fresco, argamassas com um bom nível de trabalhabilidade, adequado à finalidade do programa experimental. $\mathrm{O}$ uso das pérolas de poliestireno expandido reduziram a densidade da argamassa no estado fresco, assim como reduziram a densidade aparente das placas no estado endurecido. Portanto, do ponto de vista dos experimentos realizados, o poliestireno expandido apresentou-se ser um material indicado para a produção de placas cimentícias, até os teores aqui estudados, porém para validação e possível uso, faz-se necessário a realização dos demais testes que lhe são relacionados e assim também realizar verificações que possam analisar diretamente a vida útil das placas em relação ao meio e possíveis patologias.

\section{REFERÊNCIAS}

ABNT - ASSOCIAÇÃO BRASILEIRA DE NORMAS TÉCNICAS. NBR 13276: Argamassa para assentamento e revestimento de paredes e tetos - Determinação do índice de consistência. Rio de Janeiro, 2016.

ABNT - ASSOCIAÇÃO BRASILEIRA DE NORMAS TÉCNICAS. NBR 13276: Argamassa para assentamento e revestimento de paredes e tetos - Determinação do índice de consistência. Rio de Janeiro, 2016. 
ABNT - ASSOCIAÇÃO BRASILEIRA DE NORMAS TÉCNICAS. NBR 13278: Argamassa para assentamento e revestimento de paredes e tetos - Determinação da densidade de massa e do teor de ar incorporado. Rio de Janeiro, 2005.

ABNT - ASSOCIAÇÃO BRASILEIRA DE NORMAS TÉCNICAS. NBR 15498: Placa de fibrocimento sem amianto. Rio de Janeiro, 2016.

ABNT - ASSOCIAÇÃO BRASILEIRA DE NORMAS TÉCNICAS. NBR 15575-4: Edificações Habitacionais Desempenho. Parte 4: Sistemas de vedações verticais externas e internas. Rio de Janeiro, 2013.

ABNT - ASSOCIAÇÃO BRASILEIRA DE NORMAS TÉCNICAS. NBR 16541: Argamassa para assentamento e revestimento de paredes e tetos - Preparo da mistura para a realização de ensaios. Rio de Janeiro, 2016.

ASTM C1585. Standard Test Method for Mesurement of Rate Absorption of Water by Hydraulic-Cement Concretes. Annual Book of ASTM Standards, v. 04, n. 147, p. 1-6, 2004.

AZEVEDO, Afonso Rangel Garcez De. Desenvolvimento de placas cimentícias reforçadas com incorporação do lodo primário da indústria de papel de celulose. p. 168, 2018.

Banawair, A. S.; Qaid, G. M.; Adil, Z. M.; Nasir, N. A. M. The strength of lightweight aggregate in concrete - A Review. Sustainable Civil and Construction Engineering Conference. 2019.

BARbOSA, C. C. M; MENESES, M. D. Patologia em paredes de placas cimentícias, Faculdade Aldete Maria Alves , Iturama - MG, 2019.

JUNIOR, G. B. Placas cimentícias com resíduos de poliestireno expandido (EPS): Estudo das propriedades físicas e mecânicas, Universidade Federal do Espírito Santo, Vitória, 2019.

KHATIB, J.m.; HERKI, B.a.; ELKORDI, A. Characteristics of concrete containing EPS. Use Of Recycled Plastics In Eco-efficient Concrete, p.137-165, 2019. Elsevier.

MAAROUFI, Maroua et al. Characterization of EPS lightweight concrete microstructure by X-ray tomography with consideration of thermal variations. Construction and Building Materials, v. 178, p. 339-348, 2018.

PETRUCCI, E. G. R.. Concreto de cimento Portland. $14^{\text {a }}$ edição, revisada por Vlamir Antônio Paulon, ed. Globo, São Paulo, 2005.

RANJBAR, Malek Mohammad; MOUSAVI, S. Yasin. Strength and durability assessment of self-compacted lightweight concrete containing expanded polystyrene. Materials and Structures/Materiaux et Constructions, v. 48, n. 4, p. 1001-1011, 2015.

ROSSIGNOLO, J. A. Concreto Leve Estrutural: influência da argila expandida na microestrutura da zona de transição pasta/agregado. Ambiente Construído, Porto Alegre, v. 9, n. 4, p. 119-127, out./dez. 2009. 